\section{The use of a $3.5 \mathrm{~mm}$ drill sleeve to harvest bone graft}

RPR Boyd, DJS Avis, HV Dabke

Salisbury NHS Foundation Trust, UK

CORRESPONDENCE TO

Robert Boyd, E: robertboyd@doctors.org.uk

\section{BACKGROUND}

There are many indications for the requirement of bone grafting in orthopaedic practice and often only small quantities of bone are needed. Traditionally, this can involve taking autologous graft or using synthetic bone substitute. There is well recognised morbidity when harvesting from iliac and fibular donor sites $^{1}$ as well as cost implications when using synthetic graft.

\section{TECHNIQUE}

First, a narrow osteotome is used to elevate a window of cortical bone in the area where bone graft is to be taken from, approximately $0.5 \mathrm{~cm}$ in diameter. Next a $3.5 \mathrm{~mm}$ drill sleeve (as found on the standard orthopaedic small fragment set) is tapped into the created defect to remove a core of the underlying cancellous bone. Finally, passing a $3.5 \mathrm{~mm}$ drill through the sleeve allows the core of bone to be ejected and used as graft. In our example (Figs 1 and 2), the cancellous bone was taken from the distal tibia, adjacent to a complex fibula fracture that had some bone loss. The fracture went on to union with the patient having an uneventful recovery.

\section{DISCUSSION}

This is a simple technique and uses standard orthopaedic equipment. There is no need to enlarge the incision or source graft from another site. By negating the need for both bone substitute and use of further trays of osteotome sets, no extra costs are incurred. We applied this technique to a fibula fracture although the principle could be applied in other orthopaedic scenarios.

\section{Reference}

1. Ebraheim NA, Elgafy $\mathrm{H}, \mathrm{Xu}$ R. Bone-graft harvesting from iliac and fibular donor sites: techniques and complications. J Am Acad Orthop Surg 2001; 9: 210-218.
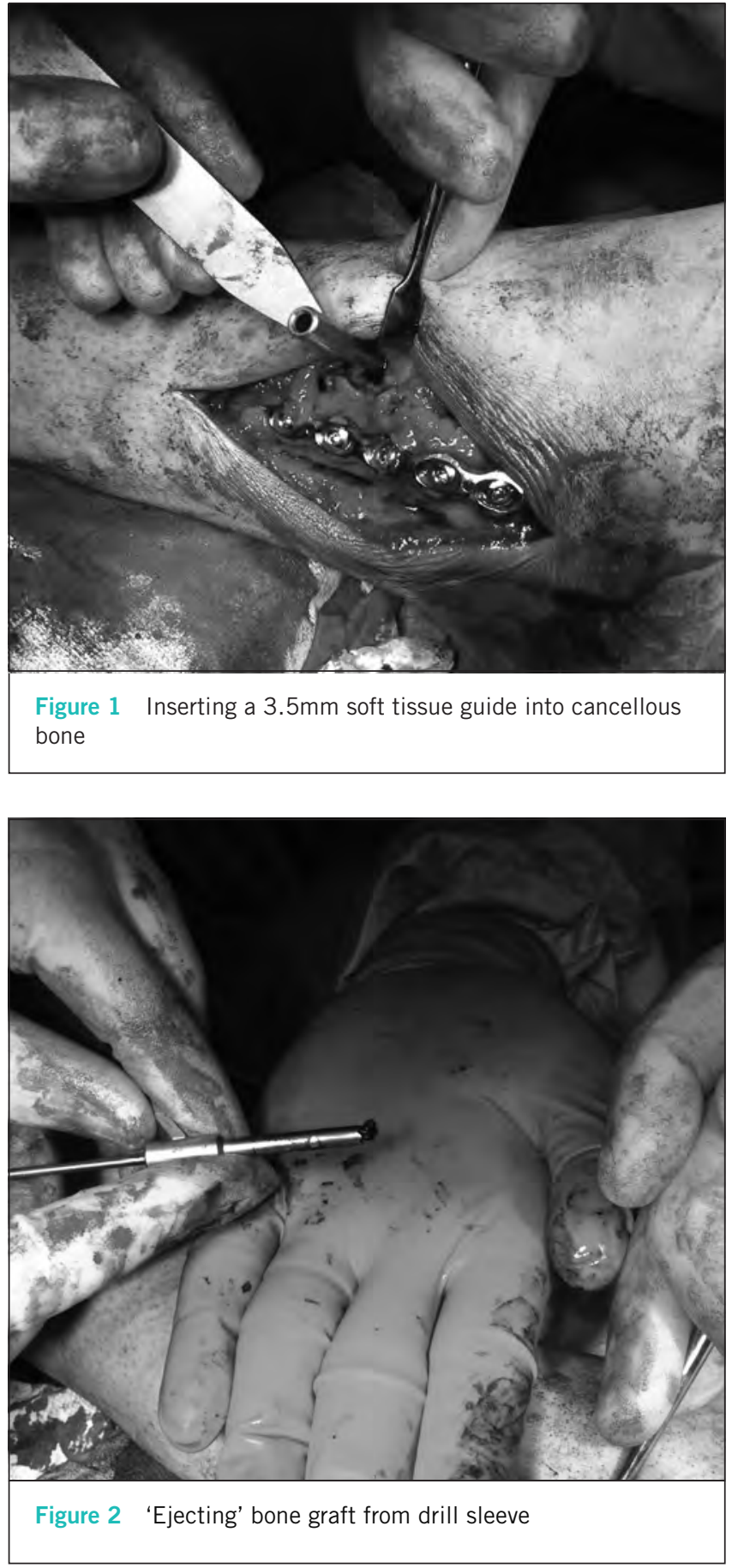